\title{
Burden of respiratory disease on hospital admission of children: Experience from a tertiary care centre
}

*Umasankar Nirubaa ${ }^{1}$

Sri Lanka Journal of Child Health, 2021; 51(4): 661-666

DOI: http://doi.org/10.4038/sljch.v50i4.9858

\begin{abstract}
Introduction: Respiratory disease is a common cause of hospital admission in children.
\end{abstract}

Objectives: To assess the burden of respiratory diseases on hospital admissions of children under 14 years at Teaching Hospital Jaffna (THJ), Sri Lanka

Method: A prospective cross-sectional study was carried out at the Professorial Unit of THJ, Sri Lanka. All the children diagnosed with the respiratory disease were recruited into the study. Data were collected from $1^{\text {st }}$ January to $31^{\text {st }}$ December 2017 by interviewer-administered questionnaire. The data were analysed using SPSS version 20.0. Results were expressed as percentages and frequencies for qualitative data and mean and standard deviation for quantitative data.

Results: Out of a total of 4127 admissions 1286 (31\%) children were admitted with respiratory illness. There was male predominance $(55.7 \%)$. Mean age of the study population was $42 \pm 39$ months. Infectious diseases contributed to $92 \%$ of hospital admissions. During the previous six-month period $79.6 \%$ had no respiratory illness, and $80 \%$ had no hospital admission. The mean distance from home to the hospital was $2.3 \pm 1.5 \mathrm{~km}$. During the ward stay oxygen was needed in $9.5 \%$ of children. Mean duration of hospital stay was $3.73 \pm 2.03$ days. Seasonal variations were seen with a peak incidence in March.

Conclusions: Respiratory illness contributes to a significant burden on hospital admission of children.

${ }^{1}$ Senior Lecturer, Department of Paediatrics,
Faculty of Medicine, University of Jaffna, Sri
Lanka
${ }^{*}$ Correspondence: unirubaa@univ.jfn.ac.lk
iD https://orcid.org/0000-0001-7118-8993

(Received on 23 October 2020: Accepted after revision on 18 December 2020)

The authors declare that there are no conflicts of interest.

Personal funding was used for the project.

Open Access Article published under the Creative Commons Attribution CC-BY CC (i) License
(Key words: Respiratory illness, Hospital admission, Burden)

\section{Introduction}

Respiratory diseases are common causes of hospital admission in children in Sri Lanka as well as worldwide. In Sri Lanka, in 2017, respiratory illness accounted for 233,154 hospital admissions in children below the age of 16 years, of which pneumonia was responsible for 9484 hospital admissions ${ }^{1}$. Pneumonia is a leading cause of death in under-5-year-old children ${ }^{2}$. Globally, pneumonia contributes to $15.6 \%$ of mortality in under-5-yearold children ${ }^{3}$. Under-5 mortality in Sri Lanka was 8.8 in 2017 and pneumonia contributed to $16 \%$ of deaths of under-5-year-old children ${ }^{4}$. Acute lower respiratory tract infections not only cause immediate problems to children but also predispose them to chronic respiratory disease later on in life ${ }^{5}$. Globally, death rates from asthma in children range from 0.0 to 0.7 per $100,000^{6}$. In Sri Lanka, a study done in the Western Province showed that 20.4\% of teenagers were diagnosed with bronchial asthma and wheezing ${ }^{7}$. Another study done in the Colombo Municipal Council area in children aged 3-5 years showed an 'ever' wheezing prevalence of $38 \%$ and a 'current' wheezing prevalence of $21.3 \%{ }^{8}$.

\section{Objectives}

This study was carried out to assess the burden of respiratory diseases on hospital admission of children under 14 years, to evaluate the spectrum of the diseases needing hospital admission and their seasonal variation and to evaluate the management and the outcomes of respiratory diseases.

\section{Method}

This prospective cross-sectional study was carried out in the Professorial Paediatric Unit of the Teaching Hospital Jaffna (THJ). All the children who were primarily diagnosed with respiratory disease by the caring consultant were recruited into the study. Data were collected from $1^{\text {st }}$ January 2017 to $31^{\text {st }}$ December 2017. The data were collected by an interviewer-administered questionnaire by data collectors. Information regarding demographic details, duration of hospital stay, number of respiratory illnesses in the past 6 months and the outcome of the children, were collected. 
Ethical issues: Study approval was obtained from Ethical Review Committee of the Faculty of Medicine, University of Jaffna (No. J/ERC/16/74/ NDR/0153). Written informed consent was obtained from the parents of the children involved in the study.

Statistical analysis: The data were analysed using SPSS version 20.0. The results were expressed as percentages and frequencies for qualitative data and mean and standard deviation for quantitative data.

\section{Results}

During the calendar year 2017 (January $1^{\text {st }}$ to $31^{\text {st }}$ December 2017) a total of 4127 children were admitted to the professorial paediatric ward. Of this, 1286 children were diagnosed with respiratory illness which contributed to $31.1 \%$ of hospital admissions. Among the study population, 706 $(55.7 \%)$ were males and $516(44.3 \%)$ were females. Figure 1 demonstrates the age distribution of the study population.

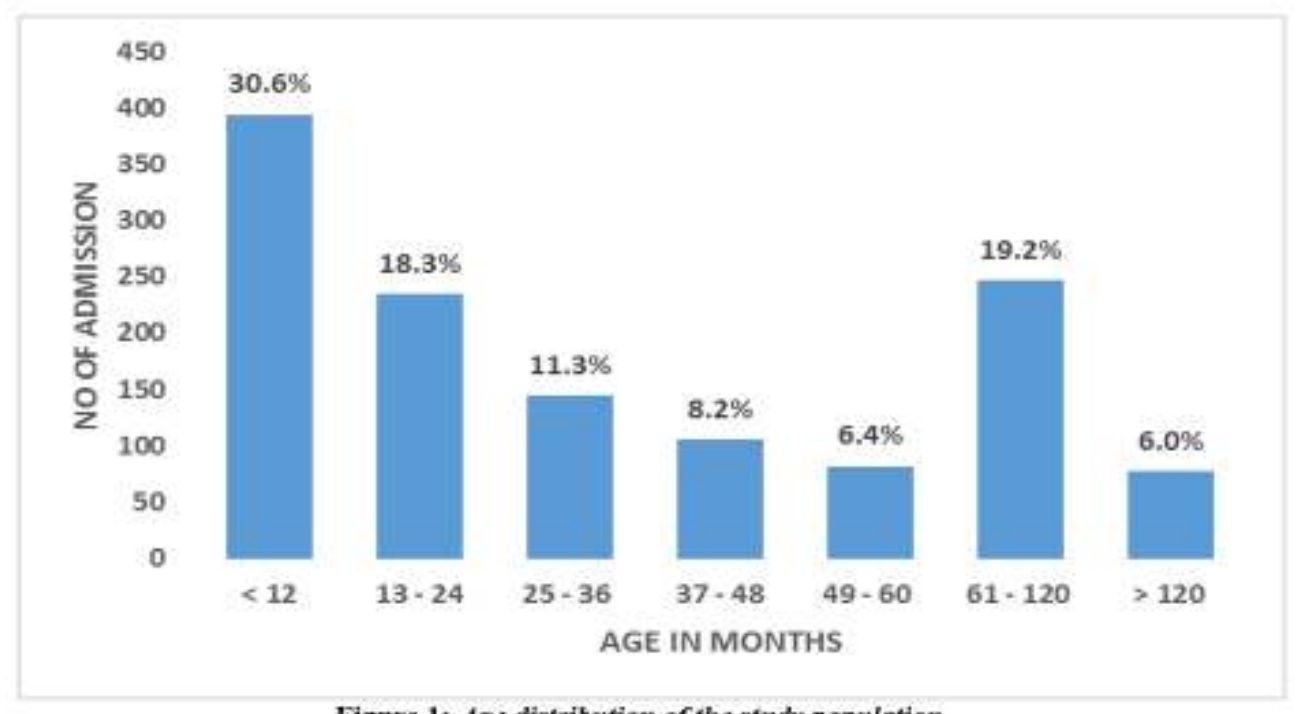

Figure 1: Age distribution of the study population

The mean age of the study population was 42 months with a standard deviation of 39 months. There were 394 (30.6\%) infants. The frequency of respiratory illness progressively decreased as the child grew older.
Most (90\%) of our study populations were born at term, $9 \%$ were born between the gestational ages of 32 and 36 weeks and only 1\% were born below the gestational age of 32 weeks. Figure 2 shows the distribution of primary diagnoses of the study population.

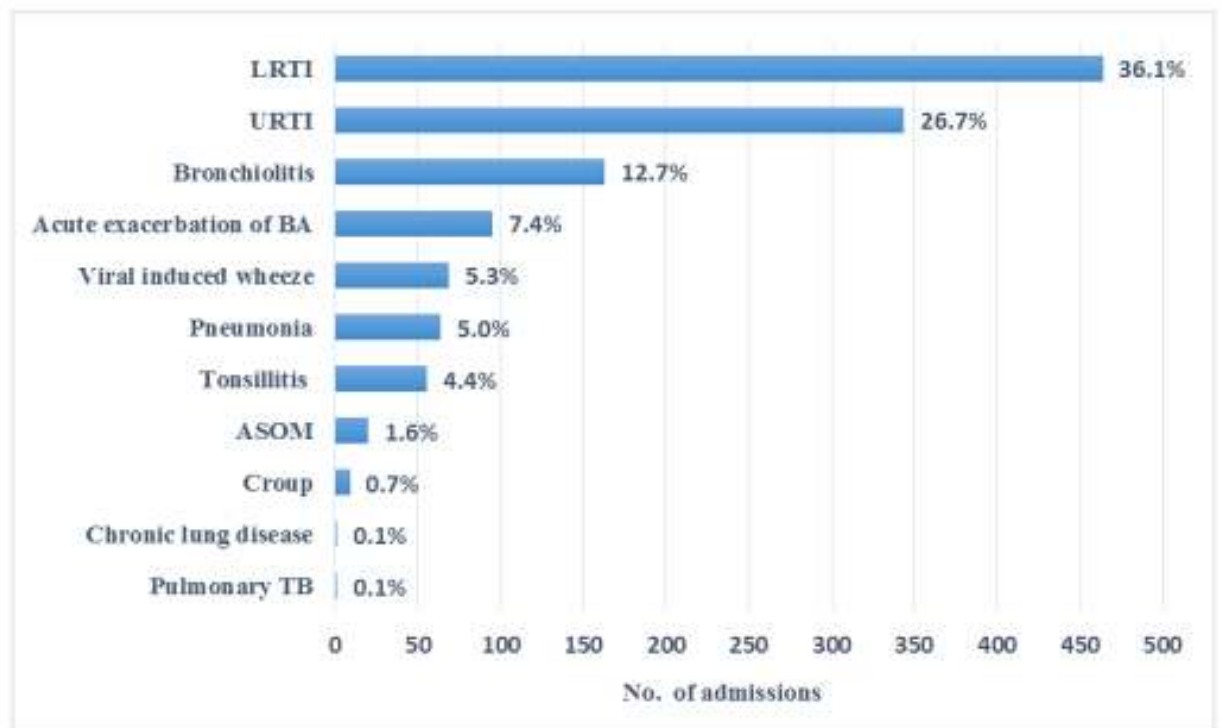

Figure 2: Distribution of the primary diagnosis of the study population LRTI: Lower respiratory tract infection, URTI: Upper respiratory tract infection, ASOM: Acute suppurative otitis media, BA: Bronchial astima, TB: Tuberculosis 
Unspecified lower respiratory tract infection (LRTI) was the most common diagnosis followed by upper respiratory tract infection (URTI). When a child presented with fever, cough and increased respiratory rate with few lung signs, but the chest $\mathrm{X}$-ray or blood investigation was not compatible with a diagnosis of bronchopneumonia or lobar pneumonia, a diagnosis of unspecified LRTI was made. However, according to WHO criteria these children would fit into the category of mild pneumonia. Infectious diseases contributed to $92 \%$ of admissions and asthma was responsible for only $7.4 \%$ of hospital admissions.

Evaluation of respiratory tract infection in the previous six months revealed that $79.6 \%$ had no respiratory illness in the previous six months, $10.7 \%$ had one episode, $5.8 \%$ had two episodes and $3.9 \%$ had three or more episodes. For $80 \%$ of the study population, this was the first hospital admission during the previous six month period. However, $12.4 \%$ had one previous hospital admission, 4\% had two hospital admissions and $3.6 \%$ had three or more hospital admissions during the previous six month period.

Distance from home to hospital varied from 1$275 \mathrm{~km}$ with a mean distance of $2.3 \pm 1.5 \mathrm{~km}$. The analysis of distance from home to hospital revealed that $37.9 \%$ of children came from the vicinity of 1 $5 \mathrm{~km}, 22.1 \%$ from $6-10 \mathrm{~km}, 21.2 \%$ from $11-15 \mathrm{~km}$, $17 \%$ from $16-50 \mathrm{~km}$ and $1.8 \%$ from more than 50 $\mathrm{km}$. Further evaluation of distance to hospital in those admitted due to URTI showed that $35 \%$ of the children with URTI came from within $5 \mathrm{~km}$ vicinity, $25 \%$ from $6-10 \mathrm{~km}, 34 \%$ from $10-20 \mathrm{~km}$ distance and $7 \%$ from more than $20 \mathrm{~km}$.

Table 1 demonstrates the children treated with antibiotics and nebulisation

Table 1: Children treated with antibiotics and nebulisation

\begin{tabular}{|l|c|c|c|}
\hline \multicolumn{1}{|c|}{ Condition } & $\begin{array}{c}\text { Total number of } \\
\text { cases }\end{array}$ & $\begin{array}{c}\text { Children treated with } \\
\text { antibiotics } \\
\mathbf{n ~ ( \% )}\end{array}$ & $\begin{array}{c}\text { Children treated } \\
\text { with nebulisation } \\
\text { n (\%) }\end{array}$ \\
\hline Lower respiratory tract infection & 464 & $464(100)$ & $288(62)$ \\
\hline Upper respiratory tract infection & 344 & $103(30)$ & $04(0.01)$ \\
\hline Bronchiolitis & 163 & $124(76)$ & $157(96)$ \\
\hline Acute exacerbation of asthma & 95 & $58(61)$ & $95(100)$ \\
\hline Viral induced wheeze & 69 & $45(65)$ & $65(100)$ \\
\hline Pneumonia & 64 & $64(100)$ & $52(81)$ \\
\hline Tonsillitis & 56 & $56(100)$ & $0(0)$ \\
\hline Acute suppurative otitis media & 20 & $20(100)$ & $0(0)$ \\
\hline Croup & 09 & $04(44)$ & $07(78)$ \\
\hline Chronic lung disease & 01 & $01(100)$ & $01(100)$ \\
\hline Pulmonary tuberculosis & 01 & $01(100)$ & $0(0)$ \\
\hline Total & $\mathbf{1 2 8 6}$ & $\mathbf{9 4 0 ( 7 3 )}$ & $\mathbf{6 6 9}(\mathbf{5 2})$ \\
\hline
\end{tabular}

All $(100 \%)$ children with pneumonia, LRTI tonsillitis, acute suppurative otitis media chronic lung disease and pulmonary tuberculosis received antibiotics; $76 \%$ children with bronchiolitis, $65 \%$ children with viral induced wheeze and $30 \%$ children with URTI also received antibiotics. All $(100 \%)$ children with acute exacerbation of asthma, viral induced wheeze and chronic lung disease and $96 \%$ children with bronchiolitis received nebulisation; $78 \%$ children with croup, $62 \%$ children with LRTI and $81 \%$ children with pneumonia also received nebulisation. During the ward stay only $9.5 \%$ of children needed oxygen.

Figure 3 demonstrates the duration of hospital stay which ranged from 1-19 days with a mean of 3.73 days and a standard deviation of 2.03 days. Most of the children needed only short stay in the hospital. Only $2.4 \%$ needed a hospital stay of 10 days or more and $31.5 \%$ needed a hospital stay of 2 days or less. 


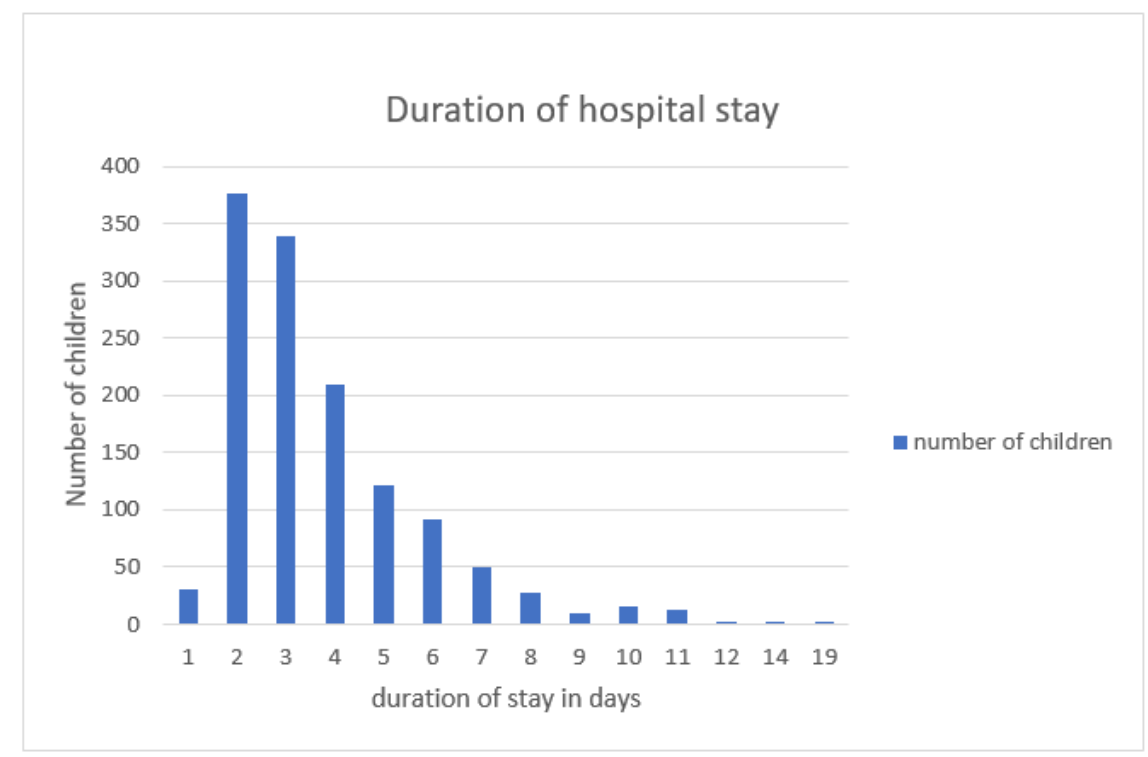

Figure 3: Duration of hospital stay

Figure 4 shows the total admissions and the respiratory admissions throughout the year.

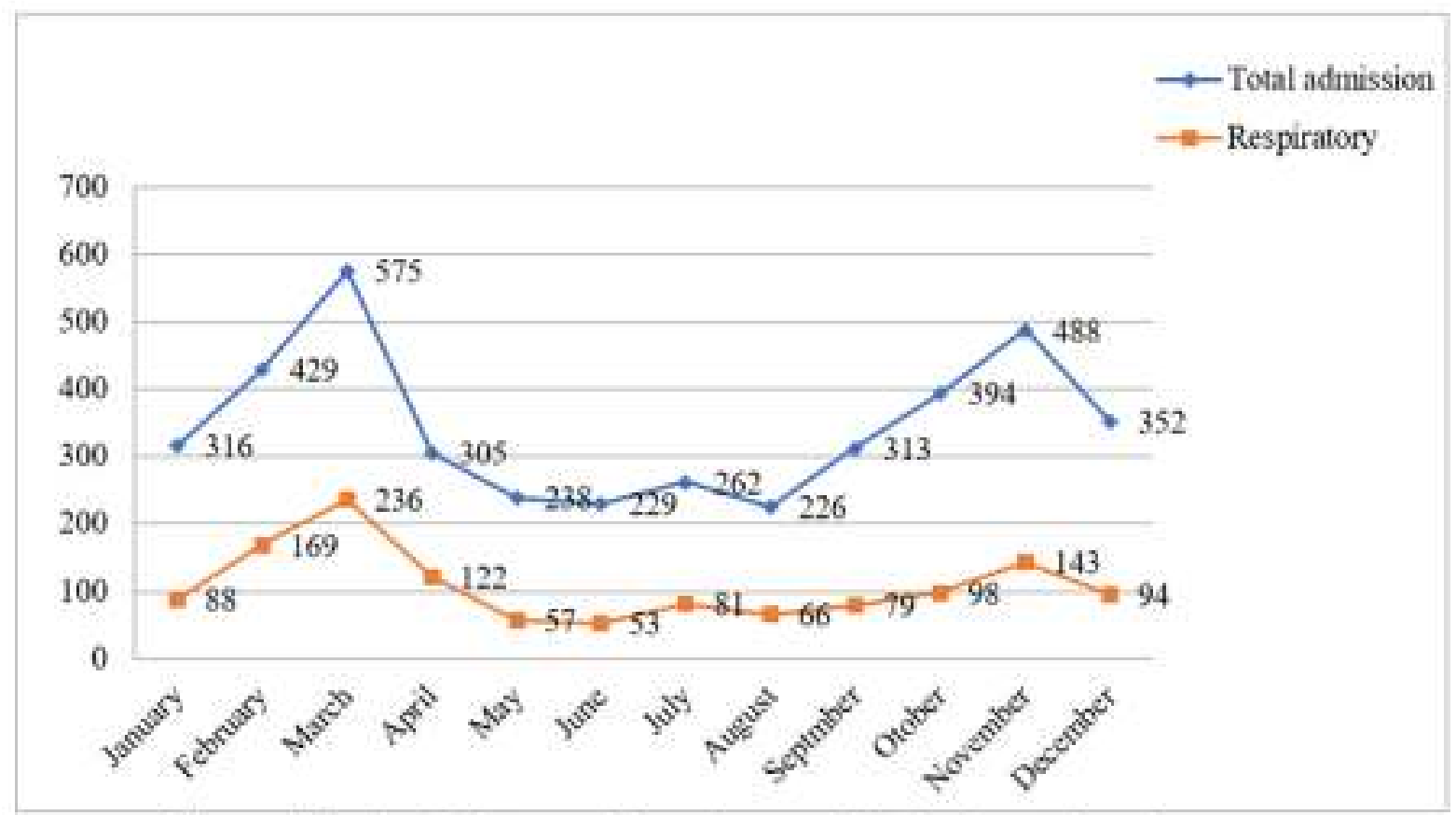

Figure 4: Total admissions and the respiratory admissions throughout the year

There were two peaks seen in total admissions. The main peak was seen in March and a smaller peak was seen in November. The respiratory illnesses mainly peaked in March and even though there was a peak in total admissions in November, the increase in respiratory illness in November was less.

During the study period only one death occurred due to pneumonia that is $0.07 \%$ in the total study population. Majority of the children (62.4\%) were discharged without any disease sequelae, and 482 $(37.5 \%)$ were discharged with follow up.

\section{Discussion}

Admissions due to respiratory illness accounted for $31 \%$ of hospital admissions. This is similar to studies done in other areas of Sri Lanka as well as worldwide where the admissions due to respiratory illness ranged from $25-35 \%{ }^{9-19}$. According to the 2017 Annual Health Statistics, Sri Lanka, respiratory illnesses are in the $4^{\text {th }}$ rank both in hospital admissions and in mortality ${ }^{1}$. Globally, too, respiratory tract infection is among the top 3 causes of death and disability among children as well as adults ${ }^{5}$. Pneumonia contributes to $15.6 \%$ of under-5 year old child mortality and it is the second 
common cause next to prematurity which contributes to $17.9 \%$. Even in adolescents 10-14 years, next to HIV/AIDS, road injury and drowning, LRTI is the leading cause of death ${ }^{3}$. In our study, other diseases responsible for hospital admission comprised other infectious disease (23.9\%), diarrhoeal illness $(9.6 \%)$, central nervous system disorders $(6.2 \%)$, renal system disorders (3.8\%), cardiovascular disease $(0.4 \%)$ and miscellaneous diseases $(25 \%)$. This indicates that one third of hospital admissions are due to respiratory illnesses and if we need to reduce the burden on hospital admission the focus should be on respiratory illnesses.

Our study revealed a slight male predominance $(54 \%)$ and infants were the vulnerable population for respiratory illness which is in keeping with other studies $^{9-19}$. This may be due to less mature immune system making the infant more susceptible to respiratory infections. Thus, our preventive strategies should be mainly focused on infants.

Communicable diseases were responsible for $92 \%$ of hospital admissions out of which non-specified LRTI was $36.1 \%$, URTI was $26.1 \%$ and pneumonia was $5 \%$. This study also revealed that $34 \%$ of URTI were admitted from $10-20 \mathrm{~km}$ distance and $7 \%$ from more than $20 \mathrm{~km}$. This indicates the need for improvement of the services of peripheral hospitals to reduce the congestion in the tertiary care centres. Improvement in the outpatient services and development of a short stay ward can also reduce the overcrowding in the paediatric wards due to respiratory illness. The observed seasonal variation in hospital total admissions, as well as admission due to respiratory illness, may be attributed to environmental factors related to factors such as rainfall and cold weather.

This study has some limitations. It was done only in a single unit, and neonatology admissions were not included as they were directly admitted to the neonatal intensive care unit and not to the general paediatric ward. Thus, the burden of respiratory illness due to neonatology case mortality, mainly due to surfactant deficiency lung diseases and pneumonia are not included in this study.

\section{Conclusions}

This study highlights the burden of respiratory illness on hospital admission in children. Even though the mortality in this study is very low $(0.07 \%)$ the morbidity is very high $(31 \%)$.

\section{Acknowledgments}

We thank the mothers who contributed to the study and the intern medical officers attached to the professorial paediatric ward THJ who helped in data collection.

\section{References}

1. Annual Health Statistics, 2017. Sri Lanka. Available from:

http://www.health.gov.lk/moh_final/englis $\mathrm{h} /$ public/elfinder/files/publications/AHB/2 017/AHS\%202017\%20final.pdf

2. Pneumonia: The forgotten killer of children. The United Nations Children's Fund (UNICEF)/World Health Organization (WHO), 2006. Available from:

https://apps.who.int/iris/bitstream/handle/1 0665/43640/9280640489_eng.pdf?sequen ce $=1 \&$ is Allowed $=y$

3. WHO: Causes of death among children. Available from:

https://www.who.int/maternal_child_adole scent/data/en/

4. Pneumonia the child killer, Weekly epidemiological report; Vol 43, No 50: 0309 ${ }^{\text {th }}$ December 2016. Available from: http://www.epid.gov.lk/web/images/pdf/w er/2016/vol_43_no_50-english.pdf

5. Forum of International Respiratory Societies. The Global Impact of Respiratory Disease - Second Edition. Sheffield, European Respiratory Society, 2017. Available from:

https:/www.who.int/gard/publications/Th e_Global_Impact_of_Respiratory_Disease .pdf

6. Asher. I, Pearce.N. Global burden of asthma among children; International Journal of Tuberculosis and Lung Disease 2014: 18(11): 1269-78.

https://doi.org/10.5588/ijtld.14.0170

PMid: 25299857

7. Mahara Hettiarachchige N S, Silva S N; Prevalence of bronchial asthma among teenagers in Western Province of Sri Lanka and its impact on school attendance; 4th International Conference on Nursing \& Healthcare; Journal of Nursing \& Care; ISSN: 2167-1168 https://www.hilarispublisher.com/proceedi ngs/prevalence-of-bronchial-asthmaamong-teenagers-in-western-province-ofsri-lanka-and-its-impact-on-schoolattendance-16719.html

8. Seneviratna R, Gunawardena NS. Prevalence and associated factors of 
wheezing illnesses of children aged three to five years living in under-served settlements of the Colombo Municipal Council in Sri Lanka: a cross-sectional study. BMC Public Health 2018; 18: 127. https://doi.org/10.1186/s12889-018-50433

PMid: 29325544 PMCid: PMC5765666

9. Karunasekera KAW, Fernando AF, Subasinghe SMV, Lakmini BC. Respiratory problems since birth to 12 years: What is causing morbidity and mortality in Sri Lanka? Sri Lanka Journal of Child Health 2014; 43(1): 33-7. https://doi.org/10.4038/sljch.v43i1.6659

10. Nelson E, Tam J, Yu LM, Li A, Chan P, Sung R. Assessing disease burden of respiratory disorders in Hong Kong children with hospital discharge data and linked laboratory data. Hong Kong Medical Journal 2007: 13(2): 114-21.

11. Oguonu T, Ayuk CA, Edelu BO, Ndu IK. Pattern of respiratory diseases in children presenting to the paediatric emergency unit of the University of Nigeria Teaching Hospital, Enugu: a case series report; BMC Pulmonary Medicine 2014; 14: 101. https://doi.org/10.1186/1471-2466-14-101 PMid: 24916799 PMCid: PMC4088915

12. Nair H, Simoes EAF, Rudan I, Gessner BD, Azziz-Baumgartner E, Zhang JSF, et al. Global and regional burden of hospital admissions for severe acute lower respiratory infections in young children in 2010; a systematic analysis, Lancet 2013; 381(9875); 1380-90.

13. Ibraheem RM, Aderemi JA, Abdulkadir MB, Johnson WBR. Burden and spectrum of paediatric respiratory diseases at a referral hospital in North-Central Nigeria A five year review. African Journal of Emergency Medicine 2020; 10(1): 3-7. https://doi.org/10.1016/j.afjem.2019.09.00 1

PMid: 32161704 PMCid: PMC7058886

14. Samoo U, Ehsan S, Agha F. Frequency and pattern of respiratory diseases in children; International Journal of
Contemporary Pediatrics 2017; 4(5):1567-71.

https://doi.org/10.18203/23493291.ijcp201 73765

15. Nguyen TKP, Nguyen DV, Truong TNH, Tran MD, Graham SM, Marais BJ. Disease spectrum and management of children admitted with acute respiratory infection in Vietnam; Tropical Medicine \& International Health 2017; 22(6): 68895 https://doi.org/10.1111/tmi.12874 https://doi.org/10.1111/tmi.12874 PMid: 28374898

16. Yousif TK, Khaleq BA. Epidemiology of acute respiratory tract infection among children under five years old attending Tikrit General Teaching Hospital. Middle East Journal of Family Medicine 2006; 14(3):

17. Baqui AH, Rahman M, Zaman K, Arifeen SE, Chowdhury HR, Begum N, et al, A population-based study of hospital admission incidence rate and bacterial aetiology of acute lower respiratory infections in children aged less than five years in Bangladesh. Journal of Health, Population \& Nutrition 2007; 25(2): 17988.

18. Krishnan A, Amarchand R, Gupta V, Lafond KE, Suliankatchi RA, Saha S, Rai $\mathrm{S}$, et al. Epidemiology of acute respiratory infections in children - preliminary results of a cohort in a rural north Indian community. BMC Infectious Diseases 2015; 15: 462. https://doi.org/10.1186/s12879-015-11881

PMid: 26502931 PMCid: PMC4624162

19. Zar HJ, Ferkol TW. The global burden of respiratory disease - Impact on child health. Pediatric Pulmonology 2014; 49(5): 430-4.

https://doi.org/10.1002/ppul.23030

PMid: 24610581 